\title{
Organization of Auditory Cortex in the Albino Rat: Sound Frequency
}

\author{
SHARON L. SALLY AND JACK B. KELLY \\ Department of Psychology, Carleton University, Ottawa, Ontario K1S 5B6, Canada
}

\section{SUMMARY AND CONCLUSIONS}

1. Responses of neurons in the auditory cortex of the albino rat were examined using microelectrode mapping techniques. Characteristic frequencies were determined for numerous electrode penetrations across the cortical surface in individual animals. A primary auditory area was identified in the posterolateral neocortex that was characterized by short latency responses to tone bursts and tonotopic organization with high frequencies represented rostrally and low frequencies, caudally. Within this area cells with similar characteristic frequencies were aligned in a dorsoventral orientation to form isofrequency contours.

2. Tuning curves obtained from primary auditory cortex were characteristically "V" shaped with $\mathrm{Q}_{10}$ 's ranging from 0.97 to 28.4 . Maximum $\mathrm{Q}_{10}$ values increased monotonically with characteristic frequency $(\mathrm{CF})$. The lowest thresholds at CF closely approximated the behavioral audiogram for the albino rat. Many neurons, however, had CF thresholds well above the behavioral limit.

3. Areas were found dorsal and ventral to the primary auditory cortex in which CF's were clearly discontinuous with the neighboring isofrequency contours. These data suggest the presence of other auditory fields, the detailed characteristics of which have yet to be examined.

\section{INTRODUCTIOON}

The albino rat has been used recently in a number of behavioral studies of auditory cortex $(27,32,33,36)$. The effects of both bilateral and unilateral auditory cortical lesions on sound localization ability have been examined. The effects of disrupting thala- mocortical projections to auditory cortex by bilateral destruction of the medial geniculate body have also been investigated (34). The results of these studies reveal only minor impairments in sound localization compared with the severe deficits reported for other mammalian species following ablation of the auditory cortex $(18,19,25,26,28-30,54$, $55,64,66,68)$.

The rat has also been the subject of a number of neuroanatomical studies that indicate that the thalamocortical auditory system is quite similar to that in other mammals. In terms of both cytoarchitecture and afferent and efferent connections, the rat's auditory cortex conforms to the basic mammalian plan $(3,9,13-15,40,42,43,61-63,69)$. On the other hand, detailed electrophysiological studies of the rat's auditory cortex are almost completely lacking. An abstract by LeMessurier (44), summarized by Woolsey (70), reports the presence of auditory cortex in the rat as defined by evoked potential mapping techniques. More recent microelectrode studies have provided partial maps of auditory cortex $(2,65)$, but a complete map of auditory cortex has never been published, and quantitative data on response properties are lacking. The purpose of the present study is to provide basic information regarding the organization of the auditory cortex in the rat using microelectrode mapping techniques.

\section{METHODS}

\section{Animal preparation}

Experiments were conducted on 25 male Wistar albino rats obtained from Charles Rivers Laboratory, St. Constant, Quebec. Immediately before surgery the external ears and the tympanic membranes were examined with an otoscope and determined to be free of discase or obstruction. 
Surgical anesthesia was induced with Equithesin ( $3 \mathrm{ml} / \mathrm{kg}$ ip) and maintained with supplemental doses $(0.5 \mathrm{ml} / \mathrm{kg}$ ip $)$ administered approximately every $40 \mathrm{~min}$ up to a period of $13-18 \mathrm{~h}$. Equithesin, obtained by us from Jensen-Salsbery Labs, is no longer commercially available. However, a $500-\mathrm{ml}$ aqueous solution containing $21.3 \mathrm{~g}$ chloral hydrate, $10.6 \mathrm{~g}$ magnesium sulfate, and $4.8 \mathrm{~g}$ pentobarbital sodium may be used instead. This solution has provided reliable anesthesia over the extended time periods required for electrophysiology in virtually every animal investigated to date. A heating pad was used to regulate body temperature over the duration of the expcriment. The animal was held rigidly in a headholder that left the ears unobstructed. Following a midline incision, a wide craniotomy was performed to expose the auditory cortex. The dura was left intact to minimize brain movement. The dural surface was then coated with warmed $\left(37^{\circ} \mathrm{C}\right)$ dimethyl polysiloxane oil that was reapplied at frequent intervals. A Polaroid photograph was taken of the vasculature pattern to allow precise location of the electrode penetrations. A millimeter scale was placed on the dural surface during photography to provide later calibration and establishment of electrode positions.

During the course of the experiment each electrode penetration was guided by a view of the lateral surface of the brain through a dissecting microscope. The location of the electrode was then determined by cross reference to the brain photograph and the cortical vasculature as viewed with the dissecting microscope.

At the termination of each experiment the animals were given a lethal dose of Equithesin. The brain was removed without perfusion and fixed by immersion in $10 \%$ Formalin. The fixed brains were photographed to relate the overall cortical vasculature to the areal extent of auditory cortex.

\section{Details of stimulus and recording techniques}

Continuous sine waves from a Hewlett-Packard function generator (HP 3310A) were shaped by a Coulbourn Instruments electronic gate (S84-04) to form tone bursts of 110 -ms duration including $10-\mathrm{ms}$ rise and decay times. In studies of cells tuned to very low sound frequencies (less than $\sim 750 \mathrm{~Hz}$ ) the risc/decay times were extended to 20 or $50 \mathrm{~ms}$ to eliminate gating transients. Stimulus repetition rate was $1 / \mathrm{s}$.

The signals were amplified and transduced by KEF high-frequency (type SP 1032) and midrange (type AD5060) loudspeakers located in the horizontal plane 16 in. from the pinna and $30^{\circ}$ contralateral to the exposed hemisphere in line with the apparent acoustical axis of the pinna. Measurements of tone intensity in dB SPL (sound pressure level in decibels re $0 \mu \mathrm{Pa}$ ) were obtained using a Bruel and Kjaer 0.5 in. condenser micro- phone (type 4133) situated in place of the rat's head. Stimulus amplitudes were set in $\mathrm{dB}$ attentuation during the experiment and were converted to $d B$ SPL off line. The maximum output of the stimulating system rose from $67 \mathrm{~dB}$ at 50 $\mathrm{Hz}$ to $114 \mathrm{~dB}$ at $400 \mathrm{~Hz}$, declined to $102 \mathrm{~dB}$ at 2 $\mathrm{kHz}$, and with the exception of a single $20 \mathrm{~dB}-$ deep, $300-\mathrm{Hz}$ wide trough at $7.1 \mathrm{kHz}$, was $\pm 6 \mathrm{~dB}$ to $32 \mathrm{kHz}$. The upper limit of the system was 63 $\mathrm{kHz}$ at $64 \mathrm{~dB}$ SPL. Thus the acoustical system was capable of delivering sound throughout most of the rat's hearing range (37).

Insulated tungsten microelectrodes (1.3-2.1 megohm at $1 \mathrm{kHz}$ ) wcre introduced into the cortex perpendicular to the cortical surface. Neural potentials were amplified $\times 10,000$ by a BAK amplifier (model MDA-4) and displayed on an oscilloscope. For each electrode penetration, the characteristic frequency (CF is the frequency at which the neural action potentials have their lowest excitatory SPL) was determined for single neurons or small clusters of neurons by examination of the stimulus-synchronized spike record on an oscilloscope and by listening to the amplifier output fed into a loudspeaker. For some neurons a detailed frequency tuning curve was obtained. Tuning curves were generated by the assessment of threshold excitatory responses for tone frequencies over a 60-80 dB range of SPL's. Minimum response latencies were obtained by reading first-spike times from a stimulus triggered oscilloscopc. A window discriminator and a Tracor Northern signal averager ( $\mathrm{TN}-1550)$ were used to obtain poststimulus-time histograms with bin times of $0.5 \mathrm{~ms}$.

\section{RESULTS}

The majority of neurons encountered in the rat's auditory cortex had low levels of spontaneous activity and responded to stimulus onset with a single transient burst of action potentials. The strongest responses were obtained from the middle cortical layers at a depth of $\sim 500 \mu \mathrm{m}$. The latencies to first spike in these neurons, after correction for the travel time from the loudspeaker to the external meatus, were between 8 and $14 \mathrm{~ms}$ in $>80 \%$ of the units sampled. In many cases the initial short-latency response was followed by weaker stimulus-locked responses with latencies of $100 \mathrm{~ms}$ or more. An example of this pattern of response is shown in Fig. 1. The initial short-latency response in this unit's poststimulus-time histogram was followed by a period of suppression and four discrete bursts of activity separated by 


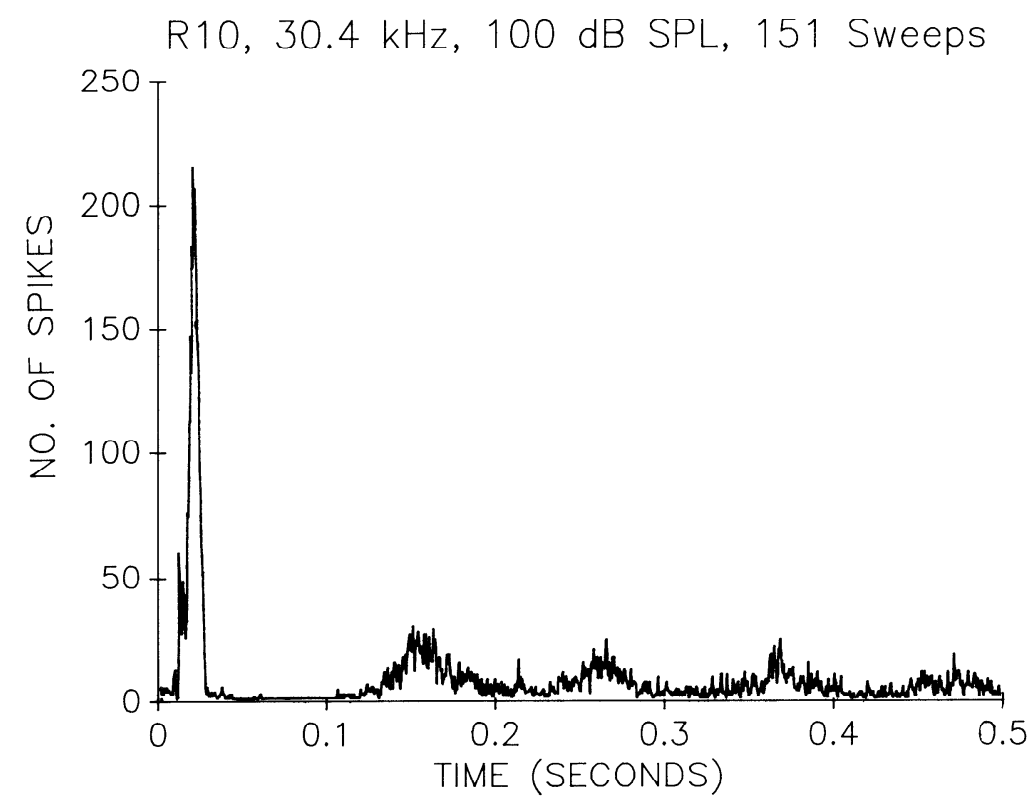

FIG. 1. Poststimulus-time histogram for a single neuron with characteristic frequency $(\mathrm{CF})=30.4 \mathrm{kHz}$ at $100 \mathrm{~dB}$ sound pressure level (SPL). $Y$-axis shows cumulative number of spikes over 151 stimulus presentations.

$\sim 105 \mathrm{~ms}$. The long-latency components of chamber. In the example shown in Fig. 1, the these responses were clearly not related to the same temporal pattern of responding was duration of the stimulus, to stimulus offset, elicited by tone bursts as brief as $10 \mathrm{~ms}$. or to any reverberation or echo in the sound Infrequently, we encountered poststimu-

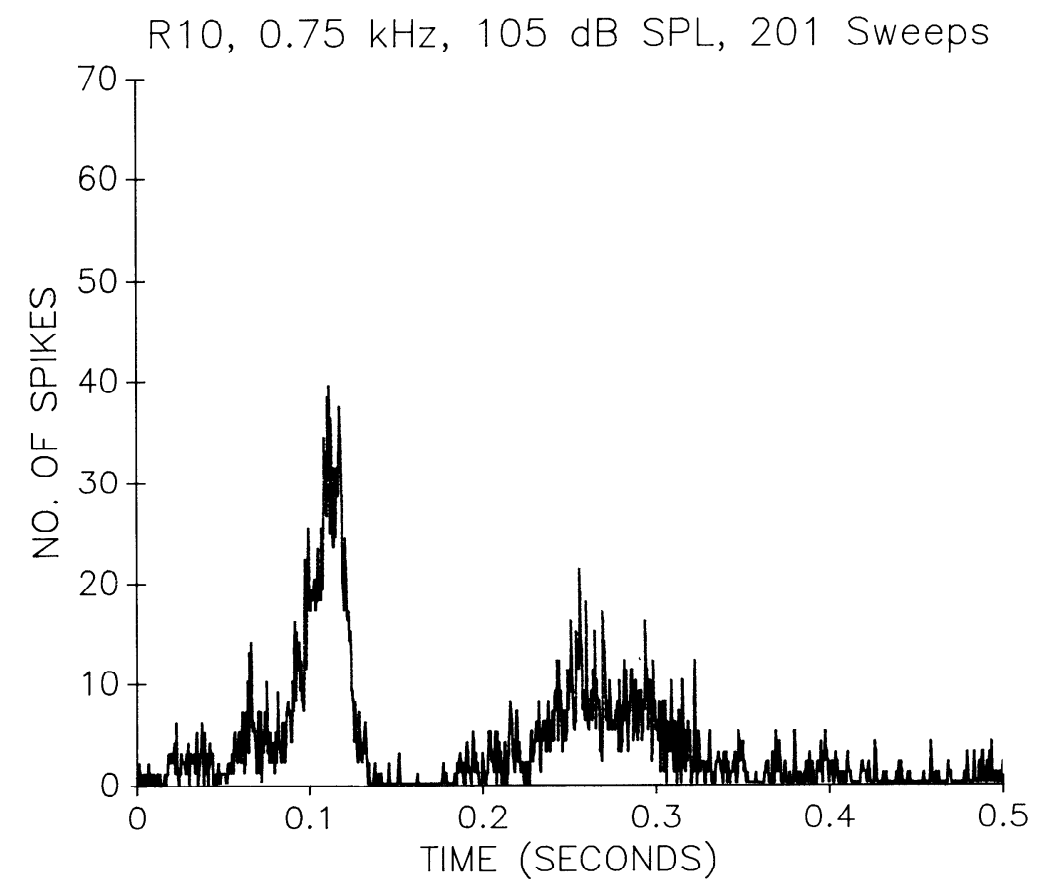

FIG. 2. Poststimulus-time histogram for a single neuron with $\mathrm{CF}=0.75 \mathrm{kHz}$ at $105 \mathrm{~dB}$ SPL. Y-axis shows cumulative number of spikes over 201 stimulus presentations. 
lus patterns that lacked any pronounced short-latency component, but that, nevertheless, could be characterized with regard to frequency response on the basis of longer-latency activity. These response types were typically found at the boundaries of auditory cortex as defined in our preparation. An example of such a response obtained from a neuron at the ventral low-frequency boundary of primary auditory cortex in rat 10 is illustrated in Fig. 2. The poststimulus histogram shows a gradual increase in activity over the first $100 \mathrm{~ms}$ followed by a second burst of activity at $\sim 255 \mathrm{~ms}$. Such response types were unusual and accounted for $<5 \%$ of the total units sampled.

Maps of characteristic frequency for five rats are shown in Figs. 3-7. Each of these animals had an acoustically sensitive area within the posterolateral neocortex charac- terized by short-latency responses and narrow tuning to sound frequencies. The area was organized in a strictly tonotopic fashion with high frequencies represented rostrally and low frequencies, caudally. The most rostral positions were associated with characteristic frequencies of $45-47 \mathrm{kHz}$, whereas the caudal boundary was associated with frequencies as low as $0.42 \mathrm{kHz}$. High frequencies occupied a much larger area of cortex than low frequencies. For example, $\sim 80 \%$ of the acoustically responsive area was devoted to frequencies within the upper three octaves of the rat's hearing range (from $\sim 8$ to 64 $\mathrm{kHz}$ ), leaving the representation of the lower four octaves (from $\sim 0.5$ to $8 \mathrm{kHz}$ ) to a relatively small region located in the caudal $20 \%$.

Recordings from neighboring points along a dorsoventral dimension revealed cells with similar characteristic frequencies. Although

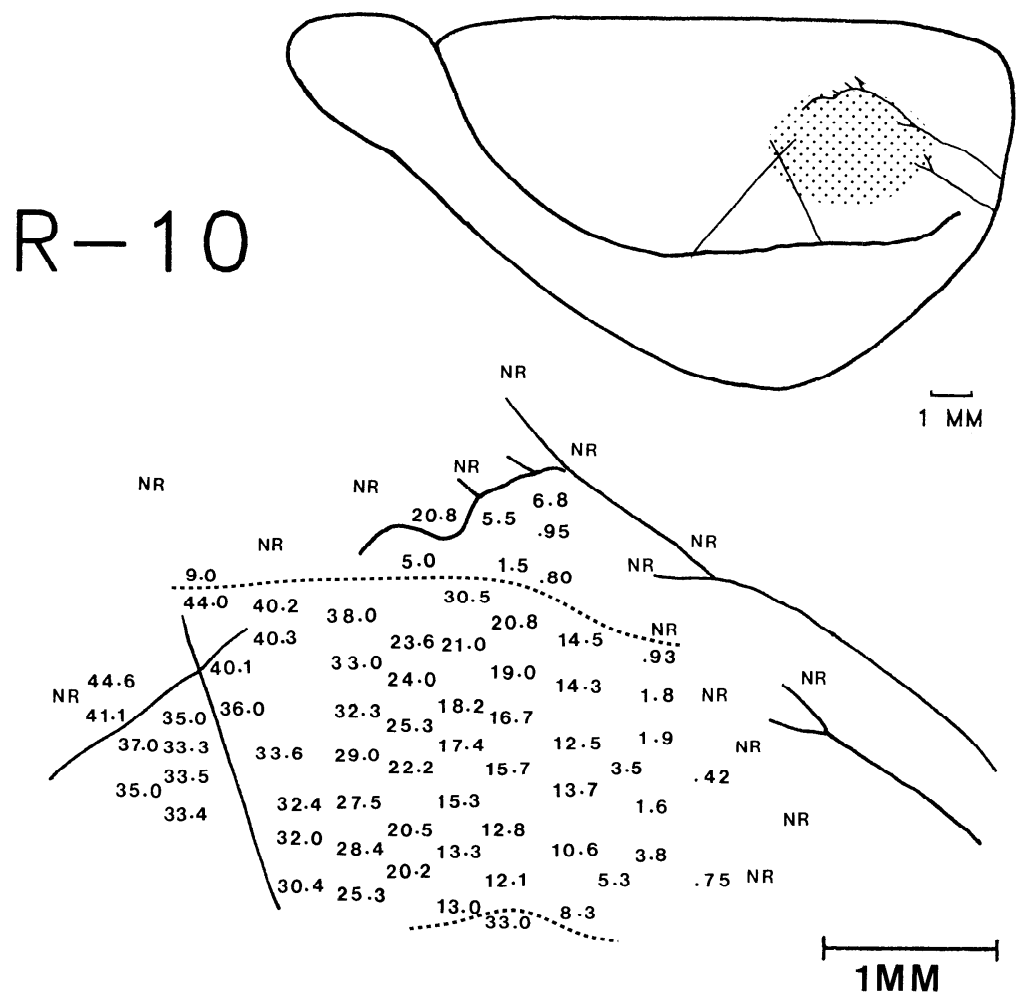

FIG. 3. Map of characteristic frequencies for rat 10. Vascular pattern on neocortex for this animal is illustrated in a standardized lateral view of the brain in the upper portion of the figure. Shading indicates the area mapped relative to vascular pattern and other landmarks. Bottom half of figure shows distribution of CF's within mapped region of the cortex. Solid lines indicate blood vessels that can be related to the vascular pattern in the standard lateral view of the brain (top). -----, Probable boundaries between subdivisions of auditory cortex as revealed by discontinuities in frequency representation. NR, no response. CF's are expressed in kilohertz. 


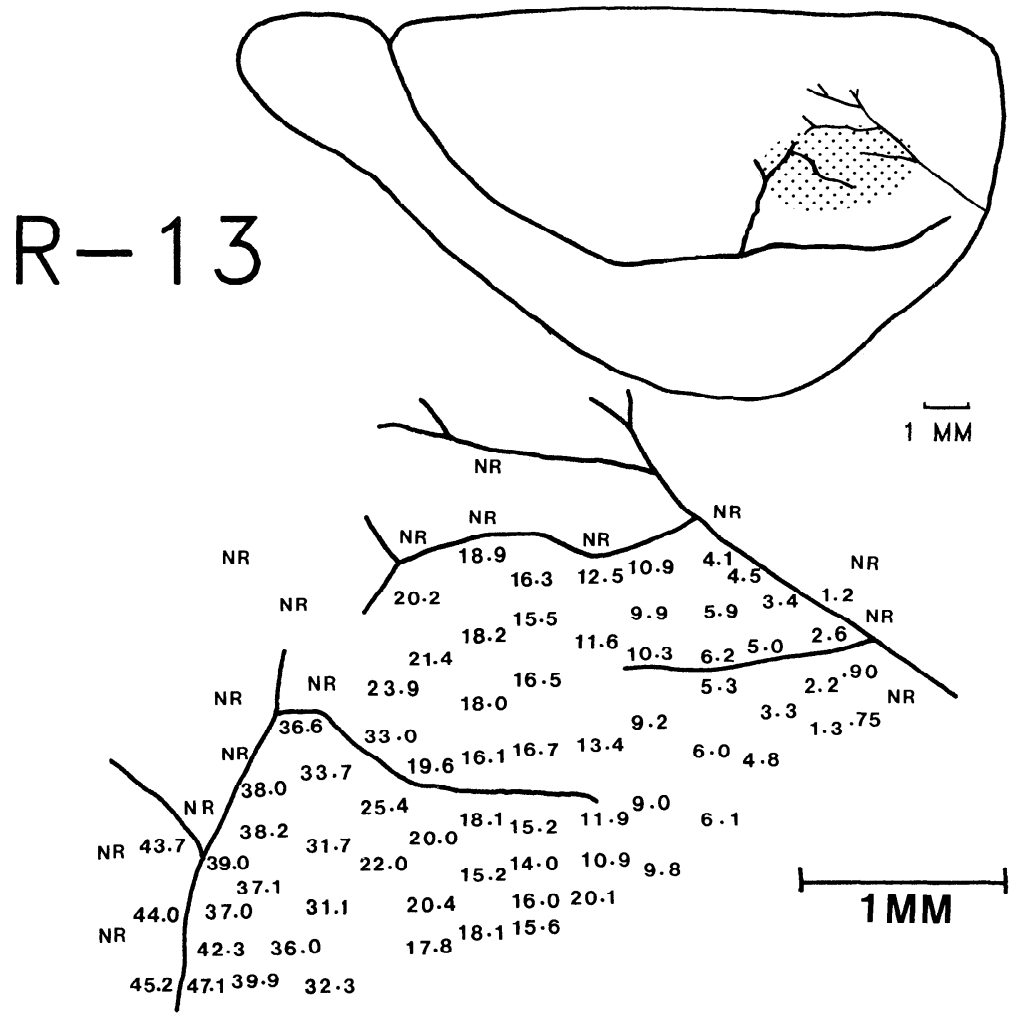

FIG. 4. Map of CF's for rat 13. Symbols are same as in Fig. 3. See Fig. 3 legend for definition of abbreviation.

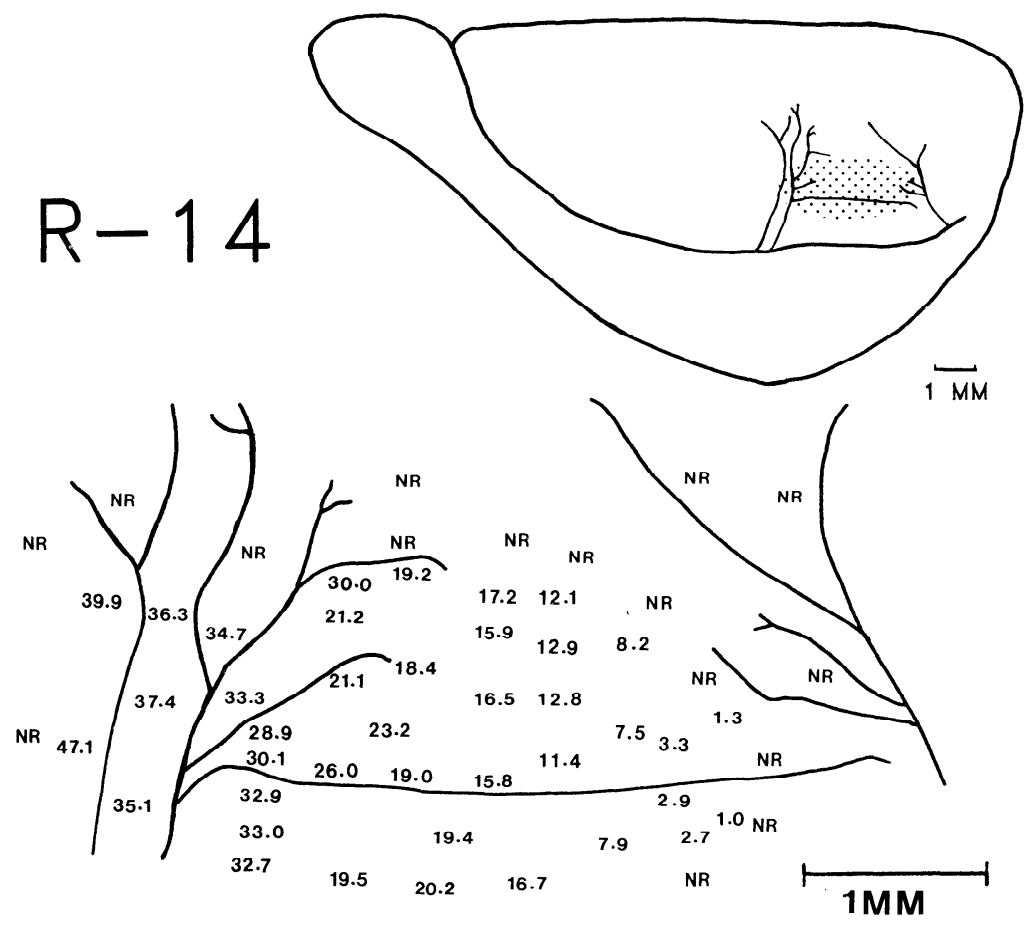

FIG. 5. Map of CF's for rat 14. Symbols are same as in Fig. 3. See Fig. 3 legend for definitions of abbreviations. 


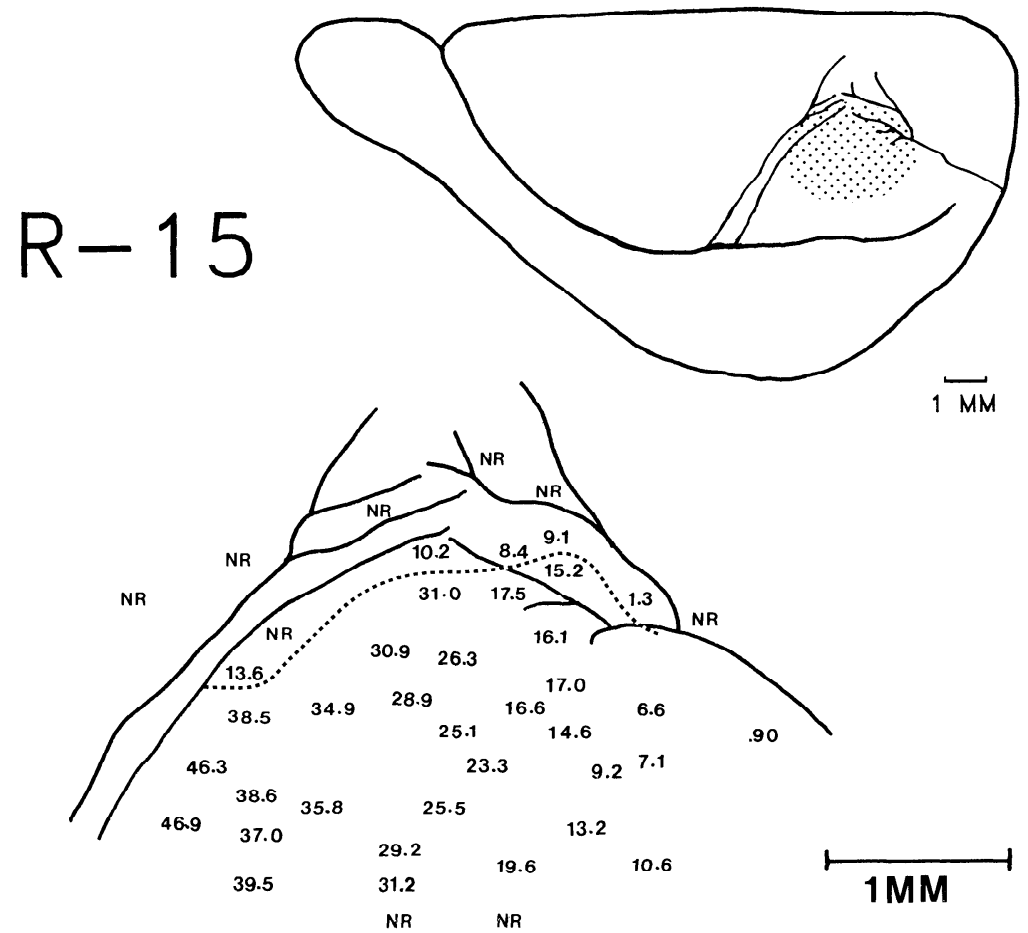

FIG. 6. Map of CF's for rat 15. Symbols are same as in Fig. 3. See Fig. 3 legend for definitions of abbreviations.
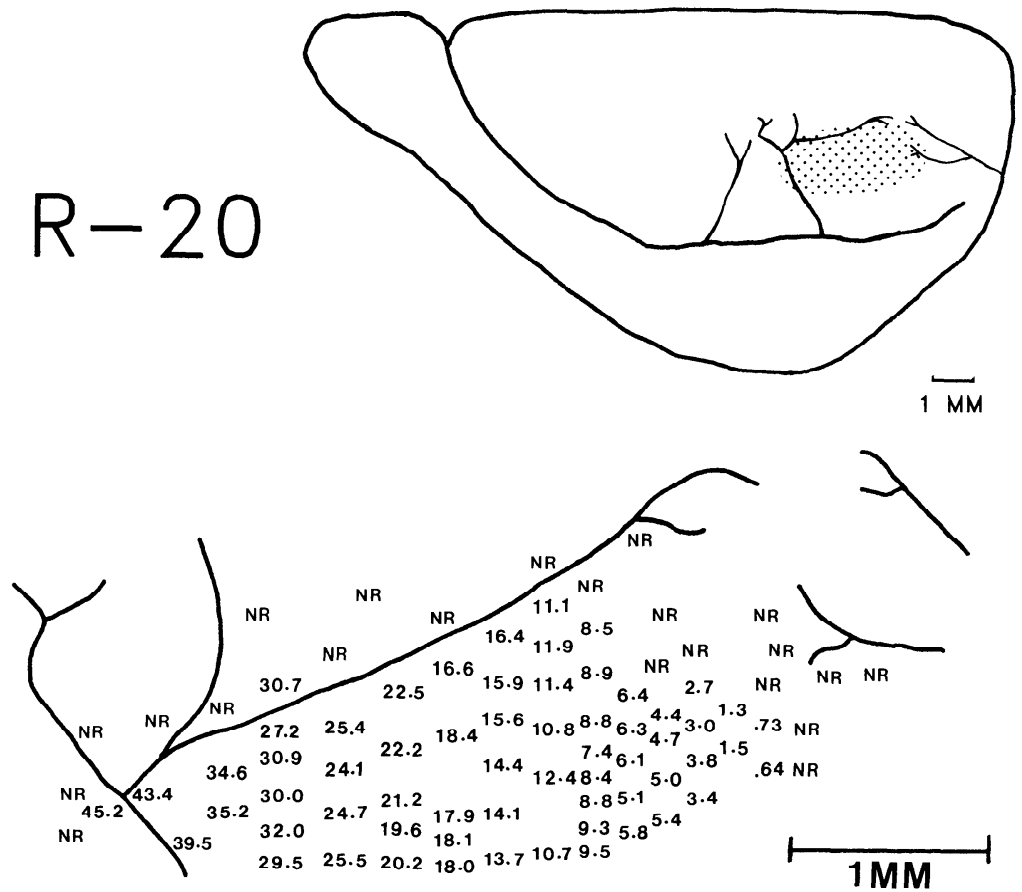

FIG. 7. Map of CF's for rat 20. Symbols are same as in Fig. 3. See Fig. 3 legend for definitions of abbreviations. 
some minor differences could be seen in the maps of individual animals, the orientation of these "isofrequency contours" was generally consistent across animals as was the general location of the auditory cortex relative to the surface vasculature. This pattern of frequency organization was confirmed in 18 additional animals (not shown) in which auditory cortex was partially mapped.

Discontinuities in the prevailing frequency trends were noted in many of the animals examined in this study including two of the five cases illustrated in Figs. 3-7. For example, the map of rat 10 clearly reveals a group of dorsally located points with relatively low CF's that are out of line with the high-frequency isofrequency contours located more ventrally (Fig. 3). In addition, a single highfrequency point $(33 \mathrm{kHz})$ was noticed along the ventral margin of the mapped area that was discrepant with more dorsal CF's. Also, the map for rat 15 illustrated in Fig. 6 gives indication of a discontinuity in the CF's of several points (e.g., 13.6, 10.2, and 8.4) located along the dorsal boundary of primary auditory cortex in an area comparable to that seen in rat 10. Similar discontinuities were seen in animals with less extensive mapping or cases mapped primarily for binaural interaction (unpublished observations). These cases suggest the presence of additional auditory areas located dorsal and ventral to the primary tonotopic field.

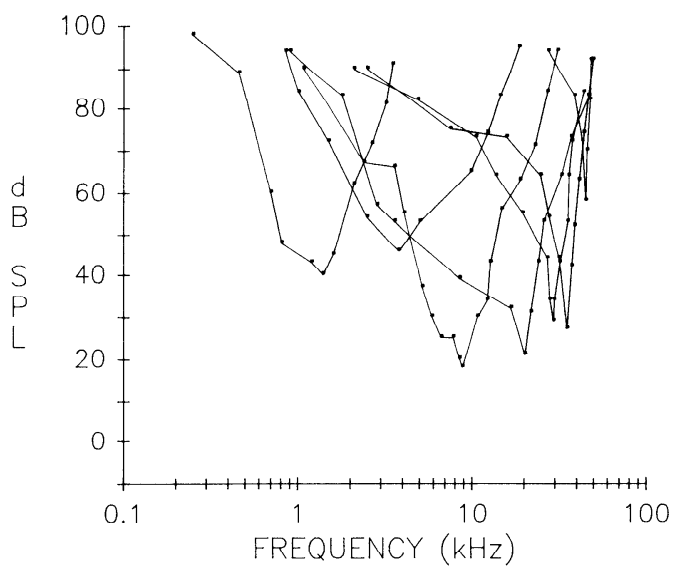

FIG. 8. Tuning curves for single neurons located in the primary auditory cortex of rat 20 . Each curve depicts the minimum sound pressure required to elicit an excitatory response at different tone frequencies.

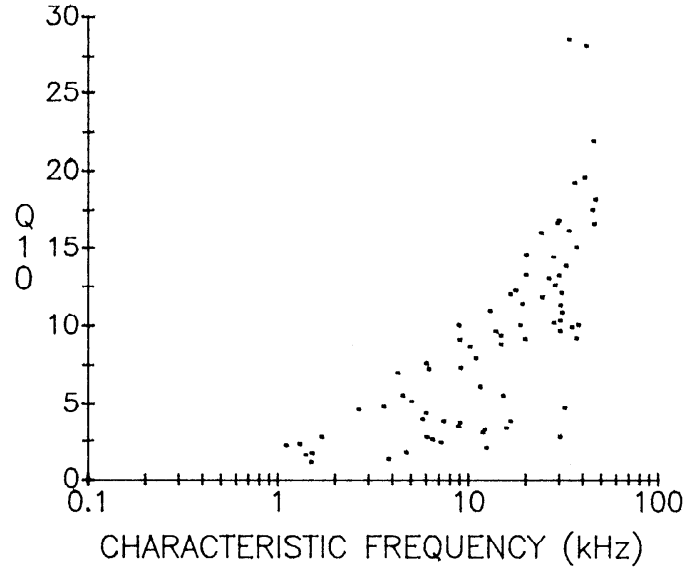

FIG. 9. Sharpness of tuning for neurons and neuron clusters at different sound frequencies. Sharpness of tuning is expressed as $Q_{10}\left(Q_{10}=C F /\right.$ bandwidth of the tuning curve at $10 \mathrm{~dB}$ above threshold).

Tuning curves were obtained from single neurons at various rostrocaudal locations within the tonotopically organized region of auditory cortex. The typical tuning curve was " $V$ " shaped with the breadth of frequency response increasing systematically with increased SPL. The shapes of tuning curves with different CF's obtained from the auditory cortex of a single animal (rat 20) are shown in Fig. 8. Curves for lower frequencies were largely symmetrical around $\mathrm{CF}$, but those for frequencies above $\sim 10 \mathrm{kHz}$ exhibited gradually sloping low-frequency tails. The tuning curves for high-frequency neurons were narrower than those for lowfrequency cells at near-threshold SPL's.

In Fig. 9 the sharpness of tuning was expressed as $Q_{10}(C F /$ bandwidth of the tuning curve at $10 \mathrm{~dB}$ above threshold) for all tuning curves obtained in this study. The figure combines data from seven different animals and includes only recordings from clearly isolated single neurons. The $\mathrm{Q}_{10}$ values ranged from 0.967 to 28.4 with the largest values associated with high sound frequencies.

Thresholds for eliciting excitatory neural responses at $\mathrm{CF}$ were determined for virtually every electrode penetration. Threshold data for the five animals with the most complete maps of auditory cortex (rats 10, 13, 14, 15, and 20) are plotted in Fig. 10A together with a previously published behavioral audiogram obtained by the conditioned sup- 


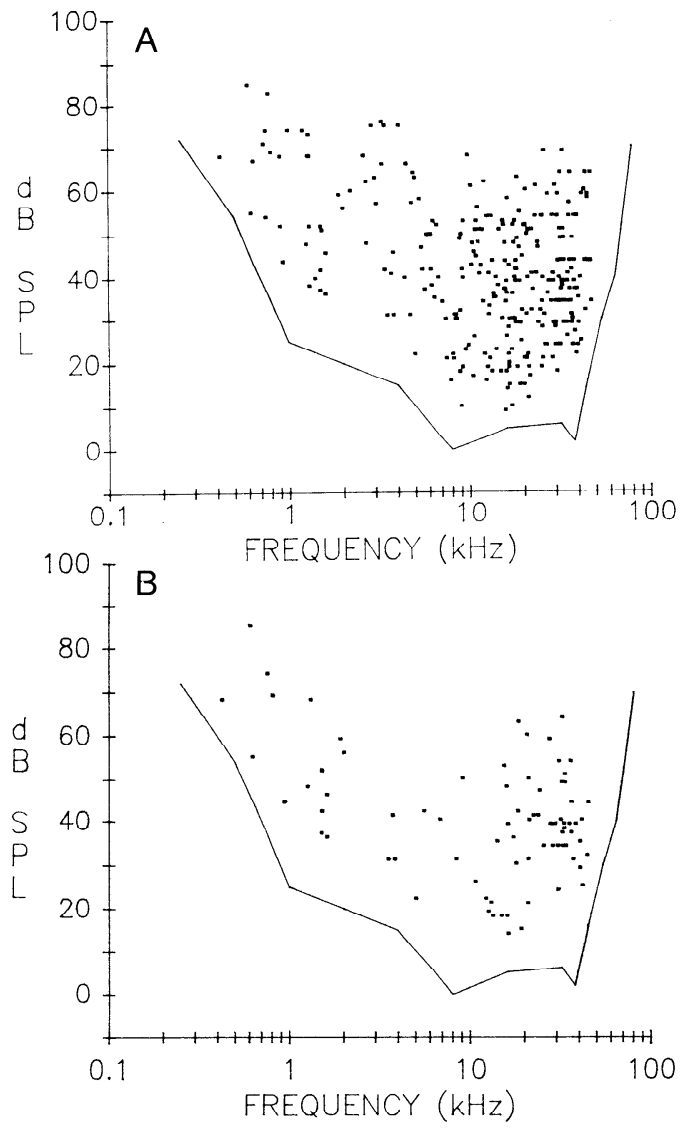

FIG. 10. $A$ : thresholds for eliciting excitatory responses at $\mathrm{CF}$ for neurons sampled from auditory cortex of 5 separate animals. •, threshold data for a single electrode penetration; - average behavioral audiogram obtained by Kelly and Masterton for the albino rat (37). $B$ : threshold data for neurons obtained from a single animal, rat 10 .

pression method (37). A close correspondence was evident between the lowest physiological thresholds at a given CF and the behavioral absolute threshold at the same frequency. On the other hand, it is clear that the CF thresholds varied widely at any particular sound frequency and covered a range of sound pressures well above the animal's audible limit. Neurons with elevated thresholds typically increased their firing rate with increased sound pressure and had dynamic ranges comparable to that found in more sensitive units. A range of CF thresholds was also found in data from individual animals as indicated in Fig. $10 B$ that illustrates results from a single experiment with rat 10 . The $\mathrm{CF}$ thresholds in this animal were similar to those seen in other individuals and were not a product of variability in the condition of the cochlea or the physical acoustics of the sound delivery system.

\section{DISCUSSION}

Our electrophysiological mapping studies have explored an area that corresponds to the auditory cortex as defined by neuroanatomical criteria $(3,13-15,40-43,56,61,62$, 67, 69). Within this area most cells respond to pure tones with a short latency transient burst of action potentials in the Equithesinanesthetized preparation. Responses are typically narrowly tuned to sound frequency and are organized in a precisely tonotopic fashion with similar CF's aligned in dorsoventrally oriented isofrequency contours. On the basis of both response type and topographic organization the region closely resembles the primary auditory cortical subdivision, $\mathrm{A} 1$, in the cat $(5,11,22,51,57$, $59,60)$.

Dorsal to this area there appears to be an additional physiologically distinct zone characterized by responses with longer latencies and less precise frequency tuning. The cells in this region have CF's that are discontinuous with the prevailing tonotopic trend in the more ventrally located auditory cortex. In our study, such responses were not seen in every case due perhaps to the animal's level of anesthesia during the recording session, but they were clearly present in two of the five rats with complete frequency maps (rats 10 and 15) and numerous additional cases with incomplete maps. Most of the responses in this area have CF's in the range of $1-10$ $\mathrm{kHz}$ with no clear indication of tonotopic organization. The dorsal area is apparently identical to a region identified by Azizi, Burne, and Woodward (2) as the source of corticopontine fibers mediating auditory responses in the paraflocculus of the cerebellum.

Responses with CF's that are discontinuous with the prevailing frequency trend have also been found ventral to the primary auditory cortex. Only one such response is illustrated in the present study (see Fig. 7), but similar responses have been found in animals with less complete maps. Thus the possibility of an additional physiologically distinct auditory field cannot be ruled out at the present time. 
Detailed comparisons can be made between the topographic organization of the primary auditory cortex in the rat and other mammals that have been mapped to date. In the rat's primary auditory cortex, high frequencies are represented rostrally and low frequencies caudally with isofrequency contours aligned in a dorsoventral orientation. The frequencies between 8 and $40 \mathrm{kHz}$ occupy the vast majority of the primary auditory cortical surface. This disproportionate representation of sound frequency is consistent with the rat's behavioral audiogram that shows best sensitivity between 8 and $40 \mathrm{kHz}$ (37). A similar representation of sound frequency has been reported for the primary auditory cortex of cat, ferret, various species of monkey, squirrel, guinea pig, rabbit, and marsupial possum $(1,4,16,21,23,36$, $48-51,60)$. In each of these species a tonotopic organization of isofrequency contours is present, but differences are found in the specific orientation of the frequency axis. For example, in the cat, high frequencies are represented rostrally and low frequencies are represented caudally within AI. Isofrequency contours are oriented dorsoventrally [Merzenich, Knight, and Roth (51); Reale and Imig (60)]. In the ferret, on the other hand, high frequencies are represented dorsally and low frequencies ventrally with isofrequency contours running in a roughly rostrocaudal orientation [Kelly, Judge, and Phillips (35)]. Rotation of the frequency axis is also found in the marsupial possum (high frequencies, dorsal), rabbit (high frequencies, dorsal), squirrel (high frequencies, caudal), and guinea pig (high frequencies, caudal) relative to the pattern found in the albino rat. Thus, quite different orientations can be found in closely related members of the same taxonomic order (e.g., Carnivora or Rodentia).

Mirror-image reversals of sound frequencies have been described within the auditory cortex of many mammals. For example, AI in the cat is bordered rostrally and caudally by three separate regions: the anterior, the posterior, and the ventral posterior fields, each of which is tonotopically organized. The boundaries of each field can be identified in electrophysiological mapping studies by the presence of mirror-image reversals in the tonotopic sequence of CF's encountered in neighboring electrode penetrations. For example, a low- to high-frequency progres- sion might be mirrored by a high-to-low sequence in an adjoining field $(6,23)$. Similar mirror-image multiple representations have been recognized in the macaque monkey, owl monkey, marmoset monkey, and bushbaby $(1,4,24,49)$. Orderly reversals in the tonotopic sequence of CF's also occur in rodents. In the guinea pig, the rostral-to-caudal progression from low-to-high CF's through primary auditory cortex reverses at the highfrequency boundary and follows a high-tolow sequence through an additional auditory field (21). A similar reversal has been found at the dorsally located high-frequency boundary of the primary auditory cortex in the rabbit (48). Evidence of an orderly frequency reversal has also been found in the rostroventral auditory field of the grey squirrel $(47,50)$. On the other hand, Gates and Aitkin (16) reported no frequency reversals in the auditory cortex of the marsupial possum and suggested that this primitive species may be limited to a single representation of the cochlea within the primary auditory field. Studies of auditory cortex in the ferret have so far revealed no frequency reversals, but the high frequency boundaries of AI are located within the depths of the suprasylvian sulcus and have not yet been fully explored $(35,58)$.

In the present study the tonotopic representation in the primary auditory cortex of the rat failed to show any obvious mirrorimage reversals comparable to that seen in many other mammals. Exploration of rostral and caudal boundaries of the primary auditory cortex revealed zones that were largely unresponsive to acoustic stimulation in the anesthetized preparation. Of course, this does not exclude the possibility that additional frequency maps may become apparent under other recording conditions or with another anesthetic. Indeed, in our most recent studies we have found evidence of high-frequency responses caudal to the auditory areas described here. Thus, although our present observations do not show mirrorimage frequency reversals within the rat's auditory cortex, the possibility cannot be excluded that such areas do exist.

Within the primary auditory cortex, the tuning properties of single neurons are generally similar for rat and cat. Tuning curves exhibit a typical "V" shape with responses determined by a narrow band of sound fre- 
quency at low SPLs, and a progressively wider range of frequencies at higher SPL's. The $Q_{10}$ measure of frequency selectivity (characteristic frequency/bandwidth at 10 $\mathrm{dB}$ above threshold) increases as $\mathrm{CF}$ increases in both rat and cat (57). The $Q_{10}$ values encountered in the present study are similar in magnitude to those reported by Møller $(52,53)$ for the cochlear nucleus in the rat and probably reflect the frequency analysis performed at lower levels of the auditory system. The frequency responses in the rat's inferior colliculus have been examined by Clopton and Winfield (7) and Clopton, Winfield, and Flammino (8), but values for $Q_{10}$ are not reported. It is interesting to note that the maximum $Q_{10}$ values for the rat's auditory cortex are substantially smaller than those for the cat at comparable frequencies (57). This difference in tuning might be related to the behavioral frequency difference thresholds and/or critical ratio measurements obtained for the two species. Elliot, Stein, and Harrison (10) have estimated that the average ratios of frequency difference threshold to sound frequency $(\mathrm{DF} / \mathrm{F})$ in the cat range between 0.007 and 0.017 , whereas ratios for the same frequencies in the albino rat are between 0.06 and $0.08(12,20,31)$. Also, the critical ratio in the rat is about three times larger than in the cat (17).

The thresholds for eliciting excitatory responses at CF can be compared with the rat's behavioral audiogram as determined by the conditioned suppression method (37). The most sensitive neurons have thresholds that are very close to behaviorally determined limits for most frequencies across the rat's hearing range. In addition, many neurons have thresholds that fall well above the behavioral curve. A wide range of neural thresholds at a given $\mathrm{CF}$ is seen not only in aggregate data but also in the data obtained from individual animals. Thus the presence of relatively insensitive neurons cannot be attributed to variation in thresholds among

\section{REFERENCES}

1. Aitkin, L. M., Merzenich, M. M., Irvine, D. R. F., Clarey, J. C., AND Nelson, J. E. Frequency representation in the auditory cortex of the common marmoset (Callithrix jaccus jaccus). $J$. Comp. Neurol. 252: 175-185, 1986. animals or to variability in the acoustics of the sound delivery system.

This pattern of responding is probably largely a reflection of the sensitivity of neurons in more peripheral auditory structures. Although we are not aware of any other study that gives the range of thresholds for neurons in the auditory system of the rat, comparison can be made to the extensive body of data from the eighth nerve in the cat $(39,45,46)$. These data have shown that most neurons with high spontaneous firing rates have thresholds within $10-20 \mathrm{~dB}$ of behaviorally determined absolute thresholds. Neurons with medium and low levels of spontaneous activity, however, have higher thresholds. Our observations do not distinguish between neurons with high and low spontaneous activity because our recordings typically revealed only transient responses with very little spontaneous activity. It seems reasonable to believe, however, that cortical responses emerge from subpopulations of neurons at a peripheral level. The threshold data from the albino rat's auditory cortex are similar to those from AI in the cat, ferret, and marmoset $(1,57,58)$.

In conclusion, we have found that the organization of the auditory cortex in the albino rat with respect to sound frequency is quite similar to that in the cat and other mammals. An area equivalent to AI has been identified that has short-latency, narrowly tuned, and tonotopically organized responses. Additional auditory areas may exist but have not been examined systematically in the present study.

\section{ACKNOWLEDGMENTS}

The authors thank Dr. D. P. Phillips for his comments on an carlier draft of this paper and G. L. Kavanagh and P. W. Judge for their help in all aspects of the project.

The study was supported by a Natural Sciences and Engineering Research Council (NSERC) operating grant to J. B. Kelly and an NSERC Summer Fellowship to S. Sally.

Received 7 May 1987; accepted in final form 23 December 1987.

2. Azizi, S. A., Burne, R. A., AND Woodward, D. J. The auditory corticopontocerebellar projection in the rat: inputs to the paraflocculus and midvermis. An anatomical and physiological study. Exp. Brain Res. 59: 36-49, 1985. 
3. BeyerL, B. D. Afferent projections to the central nucleus of the inferior colliculus in the rat. Brain Res. 145: 209-223, 1978.

4. BRUGGE, J. F. Auditory cortical areas in primates. In: Cortical Sensory Organization, edited by C. N. Woolscy. Clifton, NJ: Humana, 1982, vol. 3, chapt. 3, p. 59-70.

5. Brugge, J. F., Dubrovsky, N. A., Aitkin, L. M., AND ANDERSON, D. J. Sensitivity of single neurons in auditory cortex of cat to binaural tonal stimulation: effects of varying interaural time and intensity. J. Neurophysiol. 32: 1005-1024, 1969.

6. Brugge, J. F. And Reale, R. A. Auditory cortex. In: Cerebral Cortex, edited by A. Peters and E. G. Jones. New York: Plenum, vol. 4, 1985.

7. Clopton, B. M. And Winfield, J. A. Tonotopic organization in the inferior colliculus of the rat. Brain Res. 56: 355-358, 1973.

8. Clopton, B. M., Winfield, J. A., AND Flammino, F. J. Tonotopic organization: review and analysis. Brain Res. 76: 1-20, 1974.

9. Coleman, J., Rainer, R., And Clerici, W. J. Projection pattern of the rat auditory cortex. Soc. Neurosci. Abstr. 10: 247, 1984.

10. Elliot, D. N., Stein, L., ANd Harris, J. D. Determination of absolute intensity thresholds and frequency difference thresholds in cats. J. Acoust. Soc. Am. 32: 380-384, 1960.

11. Erulkar, S. D., Rose, J. E., and Davies, P. W. Single unit activity in the auditory cortex of the cat. Bull. Johns Hopkins Hosp. 99: 55-86, 1956.

12. FAY, R. Auditory frequency discrimination in vertebrates. J. Acoust. Soc. Am. 56: 206-209, 1974.

13. FAY-LUND, H. The neocortical projection to the inferior colliculus in the albino rat. Anat. Embryol. 173: 53-70, 1985.

14. GAMES, K. D. AND WINER, J. A. Two efferent populations in layer $\mathrm{V}$ of rat auditory cortex: cells projecting to the inferior colliculus and contralateral cortex. In: Advances in Auditory Neuroscience, IUPS Satellite Symposium on Hearing, Abstracts. San Francisco, CA, 1986, p. 85.

15. GAMES, K. D. AND WinER, J. A. Layer V in rat auditory cortex: projections to the inferior colliculus and contralateral cortex. Hear. Res. In press.

16. GATES, G. R. AND AITKIN, L. M. Auditory cortex in the marsupial possum (Trichosurus vulpecula). Hear. Res. 7: 1-11, 1982.

17. Gourevitch, G. Auditory masking in the rat. $J$. Acoust. Soc. Am. 37: 439-443, 1965.

18. HeFFner, H. E. Effects of auditory cortex ablation on localization and discrimination of brief sounds. J. Neurophysiol. 41: 963-976, 1978.

19. HefFner, H. E. AND Masterton, R. B. Contribution of auditory cortex to sound localization in the monkey (Macaca mulatta). I. Neurophysiol. 38: 1340-1358, 1975.

20. Heffner, R., Heffner, H., and Masterton, B. Behavioral measurements of absolute and frequency difference thresholds in guinea pig. $J$. Acoust. Soc. Am. 49: 1888-1895, 1971.

21. HellweG, F. C., Koch, R., ANd Vollrath, M. Representation of the cochlea in the neocortex of guinea pigs. Exp. Brain Res. 29: 467-474, 1977.

22. Hind, J. E., ROSF, J. F., DAVIES, P. W., WoOlsey, C. N., BENJAMin, R. M., Welker, W. S., AND
THOMPSON, R. F. Unit activity in the auditory cortex. In: Neural Mechanisms of the Auditory and Vestibular Systems, edited by G. L. Rasmussen and W. F. Windle. Springfield, IL: Charles Thomas, 1960.

23. Imig, T. J. AND Morel, A. Organization of the thalamocortical auditory system in the cat. Annu. Rev. Neurosci. 6: 95-120, 1983.

24. Imig, T. J., Ruggero, M. A., Kitzes, L. M., JAVEL, E., AND BRUGGE, J. F. Organization of auditory cortex in the owl monkey (Aotes trivirgatus). $J$. Comp. Neurol. 171: 111-128, 1977.

25. Jfnkins, W. M. and Masterton, R. B. Sound localization: effects of unilateral lesions in central auditory pathways. J. Ncurophysiol. 47: 987-1016, 1982.

26. Jenkins, W. M. And Merzenich, M. M. Role of cat primary auditory cortex for sound localization behavior. J. Neurophysiol. 52: 819-847, 1984.

27. Judge, P. W. AND Kelly, J. B. The effects of auditory cortical lesions on seven-choice sound localization by the rat. Soc. Neurosci. Abstr. 9: 956, 1983.

28. Kavanagi, G. L. AND Kelly, J. B. The effects of auditory cortical lesions on seven-choice sound localization by ferrets. Soc. Neurosci. Abstr. 9: 956, 1983.

29. Kavanagh, G. L. And Kelly, J. B. The effects of auditory cortical lesions on minimum audible angles for sound localization by the ferret. Soc. Neurosci. Abstr. 10: 246, 1984.

30. Kavanagh, G. L. ANd Kelly, J. B. Contribution of auditory cortex to sound localization by the ferret (Mustela putorius). J. Neurophysiol. 57: 1746-1766, 1987.

31. Kelly, J. B. The effects of lateral lemniscal and neocortical lesions on auditory absolute thresholds and frequency difference thresholds of the rat. (PhD thesis). Nashville, TN: Vanderbilt Univ. Press, 1970.

32. Kelly, J. B. Effects of auditory cortical lesions on sound localization by the rat. J. Neurophysiol. 44 : 1161-1174, 1980.

33. Kelly, J. B. and Glazier, S. J. Auditory cortex lesions and discrimination of spatial location by the rat. Brain Res. 145: 315-321, 1978.

34. Kelly, J. B. AND Judge, P. W. The effects of medial geniculate lesions on sound localization by the rat. J. Neurophysiol. 53: 361-372, 1985.

35. Kelly, J. B., Judge, P. W., AND Phillips, D. P. Representation of the cochlea in primary auditory cortex of the ferret (Mustela putorius). Hear. Res. 24: 111-116, 1986 .

36. Kelly, J. B. And Kavanagi, G. L. The effects of auditory cortical lesions on pure tone sound localization by the albino rat. Behav. Neurosci. 100: 569-575, 1986.

37. Kelly, J. B. And Masterton, R. B. Auditory sensitivity of the albino rat. J. Comp. Physiol. Psychol. 91: 930-936, 1977.

38. Kelly, J. B. and Sally, S. L. Organization of auditory cortex in the albino rat: binaural interactions. $J$. Neurophysiol. In press.

39. KIANG, N. Y. Discharge patterns of single fibers in the cat's auditory nerve. Cambridge, MA: MIT Press, 1965. (MIT Research Monograph No. 35)

40. KRIEG, W. J. S. Connections of the cerebral cortex. 
I. The albino rat. A. The topography of the cortical areas. J. Comp. Neurol. 84: 221-275, 1946.

41. LASHLEY, K. S. Thalamocortical connections of the rat's brain. J. Comp. Neurol. 75: 67-121, 1941.

42. LeDoux, J. E., Ruggiero, D. A., AND ReIS, D. J. Projections to the subcortical forebrain from anatomically defined regions of the medial geniculate body in the rat. J. Comp. Neurol. 242: 182-213, 1985.

43. LeDoux, J. E., Sakaguchi, A., And Reis, D. J. Subcortical efferent projections of the medial geniculate nucleus mediate emotional responses conditioned to acoustic startle. J. Neurosci. 4: 683-698, 1984.

44. LeMESSERIER, D. H. Auditory and visual areas of the cerebral cortex of the rat. Federation Proc. 7: 70, 1948.

45. LiBERMAN, M. C. Auditory nerve responses from cats raised in a low-noise chamber. J. Acoust. Soc. Am. 63: 442-455, 1978.

46. Libfrman, M. C. AND Kiang, N. Y. Acoustic trauma in cats. Acta Oto-laryngol. Suppl. 358: 1-63, 1978.

47. Luethke, L., Krubitzer, L., AND KaAs, J. H. Connections of auditory cortex in squirrels. Soc. Neurosci. Abstr. 11: 33, 1985.

48. MCMullen, N. T. AND Glaser, E. M. Tonotopic organization of rabbit auditory cortex. Exp. Neurol. 75: 208-220, 1982.

49. Merzenich, M. M. ANd BrugGe, J. F. Representation of the cochlear partition on the superior temporal plane of the macaque monkey. Brain Res. 50: 275-296, 1973.

50. MERzenich, M. M., KaAs, J. H., ANd Roth, G. L. Auditory cortex in the grey squirrel: tonotopic organization and architectonic fields. J. Comp. Neurol. 166: 387-402, 1976.

51. Merzenich, M. M., KNight, P. L., AND Roth, G. L. Representation of the cochlea within the primary auditory cortex in the cat. J. Neurophysiol. 38: 231-249, 1975.

52. MøLlER, A. R. Unit responses in the cochlear nucleus of the rat to pure tones. Acta Physiol. Scand. 75: 530-541, 1969.

53. Møller, A. R. Coding of sounds in lower levels of the auditory system. Q. Rev. Biophys. 5: 59-155, 1972.

54. NEFF, W. D. Behavioral studies of auditory discrimination: localization of sound in space. In: Hearing Mechanisms in Vertebrates, edited by A. V. S. de Reuck and J. Knight. London: Churchill, 1968.

55. NefF, W. D., Fisher, J. D., Diamond, I. T., AND YELA, M. Role of auditory cortex in discrimination requiring localization of sound in space. J. Neurophysiol. 19: 500-512, 1956.

56. PAtTERSON, H. A. An anterograde degeneration and retrograde axonal transport study of the cortical projections of the rat medial geniculate body $(\mathrm{PhD}$ thesis). Boston, MA: Boston Univ. Press, 1976.

57. Phillips, D. P. AND IRVINE, D. R. F. Responses of single neurons in physiologically defined primary auditory cortex (AI) of the cat: frequency tuning and responses to intensity. J. Neurophysiol. 45: 48-58, 1981.

58. Phillips, D. P., Judge, P. W., AND Kelly, J. B. Primary auditory cortex in the ferret (Mustela putorius): neural response properties and topographic organization. Brain Res. 443: 281-294, 1988.

59. Phillips, D. P., Orman, S. S., Musicant, A. D., AND WILSON, G. F. Neurons in the cat's primary auditory cortex distinguished by their responses to tones and wide-spectrum noise. Hear. Res. 18: 73-86, 1985.

60. Reale, R. A. And Imig, T. J. Tonotopic maps of auditory cortex in the cat. J. Comp. Neurol. 192: 265-292, 1980.

61. RYUGO, D. K. An attempt towards an integration of structure and function in the auditory system $(\mathrm{PhD}$ thesis). Irvine, CA: Univ. of California Press, 1976.

62. Ryugo, D. K. And Killackey, H. P. Differential telencephalic projections of the medial and ventral divisions of the medial geniculate body of the rat. Brain Res. 82: 173-177, 1974.

63. SCHEEL, M. Isofrequency laminae in the medial geniculate of the rat as shown by injections of WGAHRP into the auditory cortex. Neuroscience Lett. Suppl. 18: 245, 1984.

64. STROMINGER, N. L. Localization of sound in space after unilateral and bilateral ablation of auditory cortex. Exp. Neurol. 25: 521-533, 1969.

65. SyKa, J., Druga, R., Popelar, J., AND Kalinova, B. Functional organization of the inferior colliculus. In: Neuronal Mechanisms of Hearing, edited by Josef Syka and Lindsay Aitkin. New York: Plenum, 1981.

66. Thompson, G. C. AND CORTEZ, A. M. The inability of squirrel monkeys to localize sound after unilateral ablation of auditory cortex. Behav. Brain Res. 8: 211-216, 1983.

67. Vaughan, D. W. Thalamic and callosal connections of the rat auditory cortex. Brain Res. 260: 181-189, 1983.

68. WeGENER, J. G. Auditory discrimination behavior of brain damaged monkeys. J. Aud. Res. 4: 227-254, 1964.

69. Winer, J. A. AND LaRUe, D. T. Patterns of reciprocity in auditory thalamocortical and corticothalamic connections: study with horseradish peroxidase and autoradiographic methods in the rat medial geniculate body. J. Comp. Neurol. 257: 282-315, 1987.

70. WOOLSEY, C. N. Patterns of localization in sensory and motor areas of the cerebral cortex. In: The Biology of Mental Health and Disease, edited by C. N. Woolsey. London: Cassell, 1952. 